Onomástica Desde América Latina, n.4, v.2, julho - dezembro, 2021, p.110-129.ISSN 2675-2719 https://doi.org/10.48075/odal.v0i0.27311

\title{
A ocorrência de historiotopônimos nas ruas de Marechal Cândido Rondon' ${ }^{1}$
}

\section{The occurrence of historiotoponyms in Marechal Cândido Rondon's streets}

\author{
Juliana Caroline Kissler \\ Universidade Estadual do Oeste do Paraná \\ https://orcid.org/0000-0002-1055-2250 \\ juliana_kissler@hotmail.com \\ Lucas Matheus Salvini \\ Universidade Estadual do Oeste do Paraná \\ https://orcid.org/0000-0001-7010-433X \\ salvini.lucass@gmail.com \\ Nathascha Hoffmann Marczinski \\ Universidade Estadual do Oeste do Paraná \\ https://orcid.org/0000-0002-2733-3070 \\ marczinski.n@gmail.com
}

\section{Resumo}

Os topônimos podem revelar aspectos da cultura e da sociedade de uma localidade. Com base nisso e com interesse em desvendar curiosidades acerca da nomeação das ruas de Marechal Cândido Rondon, município da região oeste do Paraná, objetivamos investigar acontecimentos e fatos que possam ter contribuído para a escolha dos historiotopônimos das ruas da cidade constituídas por datas, além de interpretar suas enunciações, que expressam preferência às datas selecionadas. Para isto, empregamos a abordagem qualitativa e as metodologias bibliográfica e documental, uma vez que realizamos revisão de literatura com pressupostos teóricos da Toponomástica (DICK, 1992; ISQUERDO, 1997; SEIDE, 2010; BRANDÃO \& ABBADE, 2016), e da Semântica do Acontecimento (GUIMARÃES, 2002), a investigação e listagem dos historiotopônimos, bem como a coleta de informações históricas sobre a formação do município. Utilizamos um corpus formado por 14 historiotopônimos, dos quais 7 rememoram acontecimentos e comemorações nacionais, 4 estão vinculados a fatos e personalidades importantes da localidade, enquanto 3 não foram relacionados a nenhum acontecimento. Constatamos que a enunciação dos historiotopônimos nacionais está vinculada ao interesse em afirmar o município como pertencente à nação, enquanto os historiotopônimos relacionados a personalidades da história do município tinham a intenção de contribuir para caracterizá-lo como uma cidade alemã.

Palavras-chave: Toponomástica, Historiotopônimos, Semântica do Acontecimento.

\begin{abstract}
Toponyms can reveal cultural and social aspects from a certain place. Upon this and alongside with the interest of unveiling curiosities about the naming of Marechal Cândido Rondon's streets, a city located in the Paraná's west, we aimed to investigate events and facts that may have contributed to the process of choosing the city streets' historioponyms constituted by dates, besides interpreting the enunciations in them, which express preference to the chosen dates. Applying qualitative approach, bibliographic and documentary methodologies, we reviewed theorical assumptions from Toponomastic studies (DICK, 1992; ISQUERDO, 1997; SEIDE, 2010; BRANDÃO \& ABBADE,

\footnotetext{
1 Trabalho final da disciplina de Léxico-Semântica do curso de Letras - Alemão/Espanhol/Inglês da Universidade Estadual do Oeste do Paraná, campus de Marechal Cândido Rondon, ministrada pela Prof ${ }^{a}$. Drª . Márcia Sipavicius Seide.
} 
Onomástica Desde América Latina, n.4, v.2, julho - dezembro, 2021, p.110-129.ISSN 2675-2719 https://doi.org/10.48075/odal.v0i0.27311

2016) and from Semântica do Acontecimento (GUIMARÃES, 2002), investigated historiotoponyms and collected data from historic informations related to the constitution of the city. From the 14 historiotoponyms identified, 7 recall national events and commemorations, 4 are related to local important facts and personalities, while 3 of them were not related to any event. Based on that, we were able to state that the enunciation of the national hystoriotoponyms is linked to the interest of alleging that the city belongs to the brazilian nation, while historioroponyms linked to important personalities in the history of the city aim to contribute to characterizing the city as a German city. Key-words: Toponomastic, Historiotoponyms, Semântica do Acontecimento.

\section{INTRODUÇÃO}

O estudo do léxico de um idioma revela muito sobre a sociedade que o utiliza e a Onomástica, que é um ramo da Lexicologia, tem como objeto de estudo o nome próprio (SOUSA \& MARTINS, 2017) e indica aspectos culturais de determinada região, desvelando os sentidos, muitas vezes implícitos, que o uso de determinado nome gera.

Há vários tipos de nomes próprios. Entre eles, destacam-se os nomes de lugares, os topônimos que são estudados pela Toponomástica, ramificação da Onomástica que se dedica aos estudos dos nomes de lugares. Como apontado na pesquisa de Seide (2010: 5), "os nomes de lugares são plenos de significado e sentidos" e, de acordo com Sousa \& Martins (2017), os estudos dos topônimos podem revelar a cultura local na qual se inserem, especialmente quando há nomes que a enaltecem.

Levando isso em conta, nesta pesquisa, objetivamos investigar o que os historiotopônimos das ruas da cidade de Marechal Cândido Rondon (município da região Oeste do Paraná) representam, buscando, em acontecimentos históricos relacionados ao município, a motivação para a escolha destes topônimos, além de interpretar as enunciações destes. De acordo com a taxonomia de Dick (1992), estes topônimos são denominados historiotopônimos.

Diante disso, apoiamo-nos também nas contribuições de Guimarães (2002) para a Toponomástica, pois o autor explica que, quando um fato enunciado previamente como histórico pelos historiadores é escolhido como um nome de lugar, ele se torna um fato memorável, sendo legítimo afirmar que sua escolha, por parte do enunciador, está relacionada com esta intenção de 
Onomástica Desde América Latina, n.4, v.2, julho - dezembro, 2021, p.110-129.ISSN 2675-2719 https://doi.org/10.48075/odal.v0i0.27311

torná-lo algo do qual todos devem se lembrar. Dessa forma, nossa proposta é entender quais são as influências da história e da cultura da cidade para a escolha dos topônimos aqui analisados.

Semelhante à nossa proposta, outros estudos também se preocuparam com a investigação dos topônimos e seu caráter sócio-histórico-cultural no município de Marechal Cândido Rondon, como Seide (2010), que investigou a história e a motivação por trás de alguns topônimos de ruas dos distritos Novo Horizonte e Margarida, de Marechal Cândido Rondon. Além disso, a pesquisadora contribuiu em outros estudos, como o de análise quantitativa do uso de nomes próprios femininos e masculinos atribuídos às ruas do município (SILVA \& SEIDE, 2017), o da investigação dos topônimos que nomeiam edifícios da localidade (KERKHOVEN \& SEIDE, 2018) e o de nomes próprios de pessoas atribuídos às escolas da cidade (RUPPENTHAL, 2021), este último indicou ter recebido a orientação de Seide em pesquisa de Iniciação Científica voluntária por meio de nota de rodapé.

Considerando as pesquisas toponímicas já realizadas no município, percebe-se que ainda não há investigações que analisem os acontecimentos, as motivações e os significados relacionados aos historiotopônimos das ruas do município de Marechal Cândido Rondon. Desse modo, a pesquisa apresentada neste artigo procura preencher esta lacuna, uma vez que ainda não serviu de corpus para outros pesquisadores.

Para o desenvolvimento da pesquisa apresentada neste trabalho, empregamos a abordagem de pesquisa qualitativa (CHIZZOTTI, 1998) e as metodologias bibliográfica (TOZONI-REIS, 2009) e documental (KRIPKA et al., 2015).

Dessa forma, o presente trabalho está organizado em seis seções. Na primeira delas, configuramos a introdução do artigo; na segunda seção explicitamos os procedimentos metodológicos, na terceira, contextualizamos brevemente a história do município de Marechal Cândido Rondon e região; na quarta seção apresentamos a fundamentação teórica; na quinta, descrevemos e analisamos os dados e expomos resultados comparativos elaborados a partir da pesquisa, e na sexta e última seção, concluímos este artigo com as considerações finais. 
Onomástica Desde América Latina, n.4, v.2, julho - dezembro, 2021, p.110-129.ISSN 2675-2719 https://doi.org/10.48075/odal.v0i0.27311

\section{METODOLOGIA}

Como mencionado previamente na seção de introdução deste artigo, a pesquisa se ampara na abordagem qualitativa, que se caracteriza por ser aquela em que o objeto de análise não é inerte ou neutro, mas sim está embutido de sentidos e significados, estes tendo sido atribuídos por meio de uma relação entre o sujeito e o mundo real, na qual interagem aspectos objetivos e o subjetivo de apreensão da realidade (CHIZZOTTI, 1998). É por meio dela que apresentamos a relação entre os fenômenos sociais/históricos/culturais no processo da nomeação das ruas e, consequentemente, a constituição do nosso corpus.

Selecionamos o município de Marechal Cândido Rondon, localizado no Oeste do Paraná, mais especificamente a zona urbana, para a coleta de informações, devido ao fato de uma das pesquisadoras residir nesta localidade. Partindo disso, entre os três pesquisadores, surgiu o interesse e a curiosidade em relação aos acontecimentos municipais e culturais que nomeiam as ruas de Marechal Cândido Rondon.

Também nos valemos do tipo de pesquisa bibliográfica que consiste em estudar a própria fundamentação teórica, ou seja, textos como livros, artigos e estudos anteriores da área que apresentam dados que se mostram relevantes em relação ao objeto de pesquisa investigado, a fim de contribuir com a produção de conhecimento (TOZONI-REIS, 2009). Utilizando este tipo de pesquisa, fizemos o levantamento de pressupostos teóricos e do estado da arte para fundamentar a análise dos dados coletados, a ser abordado posteriormente neste artigo. Selecionamos, para esta pesquisa, o livro História e Atualidades: perfil de Marechal Cândido Rondon, de Weirich (2004), e a dissertação Motivação para a escolha de um segundo nome na antroponímia rondonense, de Frai (2016), que também abordam a cidade em questão de maneira detalhada e aprofundada sendo, por isso, relevante para o entendimento da formação da cidade e da onomástica presente nela e sendo recomendável sua leitura. 
Onomástica Desde América Latina, n.4, v.2, julho - dezembro, 2021, p.110-129.ISSN 2675-2719 https://doi.org/10.48075/odal.v0i0.27311

Ainda, utilizamos o tipo de pesquisa documental, que se configura naquela em que o pesquisador seleciona e utiliza materiais que não passaram pelo processo de análise para interpretálos e contribuir para a geração de novos dados. Quando isso ocorre, os dados analisados possuem maior credibilidade (KRIPKA et al., 2015). No caso da nossa pesquisa, foram analisados os historiotopônimos das ruas de Marechal Cândido Rondon com base em materiais que pudessem revelar a motivação por trás da escolha de tais datas para a constituição dos topônimos, como dados coletados na biblioteca municipal, no acervo Memória Rondonense, em bibliografias publicadas em diferentes meios de circulação, entre outros. Houve, ainda, a busca por materiais na Prefeitura Municipal, entretanto, as informações que nos seriam necessárias não estavam disponíveis.

O processo de coleta de dados consistiu na listagem da totalidade dos nomes que fazem homenagem às datas no município em questão, por meio da pesquisa no site Ruas do Brasil ${ }^{2}$, além da coleta de dados relacionados às datas que motivaram os nomes dessas ruas. Partindo do levantamento, dividimos nossa análise em dois momentos: primeiramente, observamos que algumas datas fazem referência a comemorações e acontecimentos nacionais e regionais e; em um segundo momento, selecionamos as datas, a princípio desconhecidas, e seguimos com a pesquisa no site Memória Rondonense e no livro História e Atualidades: perfil de Marechal Cândido Rondon (WEIRICH, 2004) para verificar quais acontecimentos são registrados nos dias que aparecerem na lista a fim de compreendermos a motivação para a nomeação dessas ruas.

Ao longo do trabalho, nossa maior limitação foi a falta de acesso aos documentos oficiais sobre a nomeação das ruas da cidade, uma vez que não podemos afirmar com certeza a motivação da nomeação, justamente devido a essa falta de acesso a documentos que nos oferecessem informações mais precisas. Em decorrência disso, apresentamos, na seção de análise dos dados, pesquisas anteriores que contribuem para a elaboração de hipóteses em nosso estudo.

\footnotetext{
${ }^{2} \mathrm{O}$ site Ruas do Brasil reúne nomes de ruas, de locais de lazer e de estabelecimentos dos municípios brasileiros. As informações ali fornecidas são obtidas e mantidas atualizadas a partir dos dados disponíveis gratuitamente em OpenStreetMap.
} 
Onomástica Desde América Latina, n.4, v.2, julho - dezembro, 2021, p.110-129.ISSN 2675-2719 https://doi.org/10.48075/odal.v0i0.27311

\section{CONTEXTUALIZAÇÃO DA PESQUISA}

O município de Marechal Cândido Rondon está localizado na região Oeste do Paraná e, de acordo com o Instituto Brasileiro de Geografia e Estatística (IBGE) (2020), possui uma população estimada em 53.495 habitantes. O censo ratifica que o município possui $747,041 \mathrm{~km}^{2}$ de unidade territorial, divididos em oito distritos: Bom Jardim, Iguiporã, Margarida, Novo Horizonte, Novo Três Passos, Porto Mendes e São Roque pertencentes à zona rural, enquanto o distrito de Marechal Cândido Rondon representa a zona urbana do município (IBGE). Em nosso estudo, investigamos os historiotopônimos das ruas do distrito de Marechal Cândido Rondon.

Em decorrência do processo de colonização da região, liderado pela Industrial Madeireira Colonizadora Rio Paraná (MARIPÁ), que incentivou a migração de trabalhadores gaúchos e catarinenses para esta localização, os municípios colonizados por esta madeireira receberam forte influência da cultura germânica (WEIRICH, 2004).

De acordo com Frai (2016), a Companhia Maripá iniciou a colonização da região no ano de 1946. Inicialmente, a região do município foi nomeada de Vila Flórida, ficou conhecida também como Zona Bonita, e em 1951, o então diretor da Companhia nomeou a cidade em homenagem ao General Marechal Cândido Mariano da Silva Rondon, devido, provavelmente, à sua contribuição ao desenvolvimento da região, quem “implantou as linhas telegráficas na região e que também combateu os revolucionários da Coluna Prestes no Oeste do Paraná” (FRAI, 2016: 22).

Em relação à cultura local, faz-se relevante ressaltar que, como explica Weirich (2004: 47), a colonizadora Maripá demonstrava certa preferência em relação às origens dos colonos convidados e incentivados a adquirir um pedaço de terra na região que seria Marechal Cândido Rondon, pois, de acordo com a pesquisa, "ao se analisar o processo de colonização constata-se uma influência política que demonstra o estilo 'marcha para o Oeste', assinalado pela preferência dada a vinda dos colonos gaúchos".

Diante disso, Weirich (2004), apoiado em Wachowicz (1987), salienta que o "elemento humano" que colonizou a região foi especificamente escolhido e que havia grande predomínio pela 
Onomástica Desde América Latina, n.4, v.2, julho - dezembro, 2021, p.110-129.ISSN 2675-2719 https://doi.org/10.48075/odal.v0i0.27311

seleção de descendentes de imigrantes alemães e italianos. Além disso, Weirich (2004) também aponta que a Companhia dividiu o espaço em áreas menores e as distribuiu de modo organizado:

O assentamento desses agricultores consistia no sistema de lotes longos, uns ao lado dos outros, onde os colonos foram agrupados de acordo com sua região de origem, etnia e religião, o que confirma o planejamento minucioso da organização dos núcleos como forma de manter a hegemonia dos moradores que comungavam de interesses comuns (WEIRICH, 2004: 47).

É possível notar, portanto, os esforços da colonizadora em garantir uma etnia específica e certa organização na formação da cidade.

Com o passar dos anos, como resultado dos esforços da colonizadora Maripá, houve um aumento demográfico significativo, como demonstra a autora, por meio de uma tabela de dados (KIRCHHEIM, 2010 apud FRAI, 2016: 23). Em 1960, Marechal Cândido Rondon tinha uma população de 12.848 pessoas e, 10 anos depois, em 1970, o município mais que dobrou o número de habitantes, registrando, naquele ano, 43.776.

A partir desses números, Frai (2016) esclarece que, com o aumento da densidade demográfica, também houve o aumento da diversidade cultural e salienta que na década de 1980, com a intenção de "retornar às raízes", em 14 de julho de 1986, o prefeito Ilmar Priesnitz aprovou a lei 1.627, regulamentada pelo decreto $n^{\circ}$ 90/1987 de 22 de junho de 1987, que determinava isenção do IPTU para os imóveis construídos no estilo "Enxaimel" e "Casa dos Alpes". Além disso, também houve a instituição da festa municipal conhecida como Oktoberfest, comemoração de origem alemã. Esse conjunto de esforços ficou conhecido como Projeto de Germanidade, na tentativa de "germanizar" o município. Esses esforços das autoridades locais em resgatar essas "raízes" pode ser entendida como uma maneira de formar uma identidade local mais germânica, como se a cidade fosse formada majoritariamente por descendentes alemães e que, por isso, teria esta característica como um aspecto identitário e identificador da cidade.

Frai (2016: 25) aponta, portanto, que “atualmente, há a falsa ideia de que a cidade de Marechal Cândido Rondon é conhecida como a cidade 'tipicamente germânica' porque houve este projeto político para a retomada da cultura germânica”. Dessa forma, esses esforços em transformar Marechal 
Onomástica Desde América Latina, n.4, v.2, julho - dezembro, 2021, p.110-129.ISSN 2675-2719 https://doi.org/10.48075/odal.v0i0.27311

Cândido Rondon em uma cidade que remete à origem alemã, acabam por excluir, além da descendência italiana que colaborou para a formação da cidade, as demais etnias que compõem sua população na atualidade.

Isso pode ser comprovado também pela pesquisa de Frai (2016), pautadas na SócioOnomástica que, por meio de estudos anteriores dela e de outros autores em relação à antroponímia da cidade, demonstram "haver poucas diferenças nas práticas de nomeação da comunidade de origem germânica em comparação à comunidade não germânica, e um número considerável de famílias formadas por pessoas de diferentes origens étnicas" (FRAI, 2016: 28).

Além disso, ela salienta que "ao contrário da identidade essencialista subjacente ao projeto político de germanização, a cidade de Marechal Cândido Rondon apresenta grande heterogeneidade cultural" (FRAI, 2016: 28), comprovando que a germanização da cidade contribuiu para o apagamento das demais etnias que a compõem.

Dessa forma, partindo dessas questões culturais que envolvem o contexto histórico da cidade de Marechal Cândido Rondon, é que nos propomos a entender quais são as motivações da nomeação de ruas com datas e qual a possível relação dessa nomeação com a consolidação da cultura local do município.

\section{FUNDAMENTAÇÃO TEÓRICA}

Como apontado previamente na introdução, nossa pesquisa se baseia em estudos da área da Onomástica, que pertence aos estudos da área da Lexicologia. A Onomástica tem o nome próprio como campo de pesquisa, e uma de suas ramificações, a Toponomástica, tem, por objeto de estudo, os nomes de lugares. Sobre esses estudos, Isquerdo (1997) explica que:

O processo de dar nome aos lugares, dada a sua importância no estudo de uma língua, acabou por tornar-se objeto de estudo de um dos ramos da Onomástica, disciplina de caráter abrangente que se ocupa da investigação da etimologia, das transformações, enfim, da explicação e da catalogação dos nomes próprios de pessoas e de lugares. Essa área de investigação bifurca-se em dois ramos. Quando se refere ao estudo dos nomes próprios de pessoas é denominada de Antroponímia e quando seu objeto de 
Onomástica Desde América Latina, n.4, v.2, julho - dezembro, 2021, p.110-129.ISSN 2675-2719 https://doi.org/10.48075/odal.v0i0.27311

estudo está centralizado no exame da origem e do significado dos nomes de lugares, recebe o nome de Toponímia ${ }^{3}$ (ISQUERDO, 1997: 30).

Reforçando tal afirmação, Sousa \& Martins (2017) apontam que a Toponomástica analisa não só a utilização de denominações, mas também busca revelar suas origens e suas evoluções no decorrer do tempo, que são movidas por motivos socioculturais, uma vez que o processo de nomeação de determinado local se dá por motivos extrínsecos às palavras, como a necessidade de descrição de um local e a realização de homenagens.

Em relação à terminologia utilizada por Isquerdo (1997), é importante que façamos uma observação sobre a atualização terminológica das áreas de estudo previamente citadas. Nas pesquisas de Dick (1992), a autora afirma que Toponímia e Antroponímia constituem campos de estudo. Entretanto, na atualidade, o termo "toponímia” é utilizado para se referir a um conjunto de topônimos, sendo "Toponomástica" o termo mais adequado para se referir ao campo de pesquisa que estuda tais topônimos. O mesmo ocorre com "antroponímia" que, atualmente, representa um conjunto de antropônimos, enquanto "Antroponomástica" nomeia o campo de estudo que o investiga (SEIDE \& LUCAS, 2018).

Além disso, Dick propõe a constituição de uma taxonomia, que serve de base para a categorização e normatização dos topônimos com base em suas características. A pesquisadora também divide os topônimos em dois grandes grupos, sendo eles os de origem física (caracterizam os nomes que dizem respeito ao ambiente físico) e os de origem antropocultural (aqueles que relacionam-se a fenômenos sociais e culturais) (DICK, 1992).

Uma das taxes propostas por Dick, dentro do grupo dos topônimos antropoculturais, é a dos historiotopônimos, aqueles que, segundo a autora, são "topônimos relativos aos movimentos de cunho histórico-social e aos seus membros, assim como as datas correspondentes" (DICK, 1992: 33). Os topônimos dessa taxe constituem o corpus analisado na presente pesquisa, mais especificamente, os do município de Marechal Cândido Rondon.

3 Atualmente, utiliza-se o termo "Toponomástica" para se referir ao campo de estudo dos topônimos, e “Antroponomástica” ao campo de estudo dos antropônimos (SEIDE \& LUCAS, 2018). 
Onomástica Desde América Latina, n.4, v.2, julho - dezembro, 2021, p.110-129.ISSN 2675-2719 https://doi.org/10.48075/odal.v0i0.27311

Acerca da escolha de datas para a nomeação de locais e suas motivações, podemos citar Guimarães (2002), que nos revela que, quando um fato histórico é escolhido para constituir um topônimo, o ato da escolha faz com que os fatos se tornem memoráveis. Esta ação de nomeação parte de um locutor ${ }^{4}$, e visa torná-la algo que mereça visibilidade, como se atribuindo importância à data escolhida. Isto evidencia que, por meio da análise dos historiotopônimos que constituem nosso corpus de pesquisa, podemos analisar quais datas históricas os locutores escolheram homenagear, o que nos revela fatos acerca da constituição histórica, social e cultural desta localidade.

Sobre isso, Guimarães esclarece que locutores são responsáveis pela nomeação das ruas de uma cidade. Para o autor, o ato de nomeação das ruas ocorre por conta de processos enunciativos que partem de dois tipos de locutores: o locutor que possui o poder de dizer, chamado pelo autor de Locutor-oficial, que é aquele que corresponde à figura que possui a capacidade legal de nomear as ruas, e ao locutor $\mathrm{x}$, aquele que ocupa este lugar enunciativo e que enunciou a lei que culmina na posterior nomeação de determinada rua (GUIMARÃES, 2002: 44).

Ainda sobre os fatos históricos e calcados nos estudos de Guimarães acerca da Semântica do Acontecimento, os autores Mendes et al. (2020) ressaltam que o processo de enunciação está relacionado a processos históricos no ato da escolha de nomes para a constituição dos topônimos, e explicam que:

Guimarães, ao incluir a história, procura constituir uma semântica enunciativa que considera a representação do sujeito na constituição do sentido; considera, assim, que o sentido de um enunciado são os efeitos de sua enunciação, segundo as condições histórico-enunciativas em que aparece (MENDES et al., 2020: 185).

Com base nisso, podemos constatar que as datas que nomeiam as ruas de Marechal Cândido Rondon não simplesmente representam acontecimentos históricos, mas sim constituem o ato de evidenciar e dar atenção a fatos escolhidos pelos enunciadores, uma vez que podemos observar a presença de historiotopônimos que apresentam informações sobre a constituição do município por

\footnotetext{
${ }^{4}$ Para Guimarães (2002), locutor é o indivíduo que ocupa o espaço da enunciação, ou seja, aquele que detém o poder de ligar nomes a lugares, estabelecendo, assim, os topônimos. No presente trabalho, em específico, os locutores mencionados são os que nomeiam ruas por meio de enunciações ligadas a datas e acontecimentos históricos, os chamados historiotopônimos.
} 
Onomástica Desde América Latina, n.4, v.2, julho - dezembro, 2021, p.110-129.ISSN 2675-2719 https://doi.org/10.48075/odal.v0i0.27311

meio da homenagem a eventos históricos que datam da colonização da região e eventos ligados a pessoas envolvidas nesse processo, e existem inúmeras outras datas que não foram utilizadas para a nomeação das ruas.

Devemos apontar que, para a Semântica do Acontecimento, as datas que constituem historiotopônimos são, antes de tudo, enunciações proferidas ao longo da História e embutidas de significados e sentidos, o que motiva a nomeação de uma rua por meio de tal data. Desta maneira, então, determinada data não constitui um processo enunciativo no ato da nomeação de uma rua, mas sim é utilizada por já constituir tal processo previamente. Sobre isso, o autor esclarece que "não é porque algo aconteceu em 7 de setembro que 7 de setembro pode ser nome de rua. Esta data torna-se nome de rua porque as enunciações de uma história enunciaram esta data como data da independência" (GUIMARÃES, 2002: 53).

Além disso, Guimarães aborda o silenciamento que ocorre no processo enunciativo, toda vez que um enunciado é utilizado para a constituição de um topônimo. O autor explica que, quando o Locutor-oficial se vale de uma enunciação para homenagear algo, está colaborando com o processo de silenciamento daquilo que não está contido nela. Este processo é assim exemplificado:

\footnotetext{
Um caso especial aqui é o de Baroneza Geraldo de Resende como nome de rua. Esta nomeação traz a enunciação de alguém como "Baroneza Geraldo de Resende", mas isto é o apagamento da nomeação específica de uma mulher para assumir uma titulação que lhe vem pelo nome do marido (..) traz o silenciamento da nomeação da mulher que se casou com Geraldo de Resende (GUIMARÃES, 2002: 48).
}

Isso se revela importante para nossa pesquisa ao analisarmos que, durante o processo de constituição do município de Marechal Cândido Rondon, fez-se presente a intencionalidade de caracterizar a cidade como tendo sido fundada exclusivamente por pessoas de ascendência germânica, o que promoveu o apagamento de povos de outras ascendências que também constituem a população da cidade e estiveram presentes no processo de colonização.

Dessa forma, como explica Frai (2016), o Projeto de Germanidade, mencionado na seção anterior, aprovado por um prefeito de ascendência alemã, teve grande influência nesse apagamento e tem contribuído para o mito de que Marechal Cândido Rondon é uma cidade tipicamente germânica, 
Onomástica Desde América Latina, n.4, v.2, julho - dezembro, 2021, p.110-129.ISSN 2675-2719 https://doi.org/10.48075/odal.v0i0.27311

quando, na verdade, foi fundada também por pessoas de descendência italiana e é constituída, atualmente, por uma variedade de etnias. Há, portanto, concomitante à exaltação da descendência alemã, esforços para o apagamento de uma parte da memória rondonense.

É possível observar tal apagamento em historiotopônimos que homenageiam datas ligadas a personalidades tidas como importantes no município (caso das datas 25 de março, 2 de abril e 9 de agosto). Sobre isso, retomamos o que foi dito previamente em relação aos processos enunciativos à luz da Semântica do Acontecimento, e apontamos que tal ato constitui uma enunciação ecoada ao longo da história, que fez com que essas personalidades adquirissem o caráter de importância e as datas atreladas a elas fossem merecedoras de homenagens. Isso, mais uma vez, contribui com o apagamento de outras pessoas que não foram homenageadas, visando caracterizar o município como sendo constituído por descendentes de alemães.

Partindo de outra perspectiva, Faggion et al. (2009) defendem:

[...] que os topônimos são reveladores da vida de uma comunidade, das escolhas feitas pelos homens e das vicissitudes por eles vividas. Eles informam a origem étnica do grupo, refletem a fidelidade para com seu universo cultural e/ou sua adesão ao novo ambiente e a tudo o que o cerca (FAGGION et al., 2009: 295).

Por fim, ainda, Carvalhinhos e Antunes (2007) mencionam que, algumas vezes, ocorre o processo de esvaziamento semântico dos topônimos, por meio do qual o significado original desses nomes se torna opaco e até mesmo irrecuperável, o que culmina na dificuldade ou impossibilidade de reconstrução etimológica desses topônimos.

Isso pode ser observado em historiotopônimos que fazem referência a mais de um acontecimento histórico, como é o caso da data 2 de dezembro, em que a passagem do tempo contribuiu para que não fosse possível apontar com exatidão a qual dos acontecimentos o topônimo está conectado. Outro caso observado é o dos historiotopônimos 8 de Abril, 10 de Abril e 13 de Setembro, em que não encontramos nenhum fato vinculado a estas datas, conforme será abordado na seção de descrição e análise dos dados.

\section{DESCRIÇÃO E ANÁLISE DOS DADOS}


Onomástica Desde América Latina, n.4, v.2, julho - dezembro, 2021, p.110-129.ISSN 2675-2719 https://doi.org/10.48075/odal.v0i0.27311

Esta seção está subdividida em dois momentos. Primeiro, descrevemos os dados coletados para, posteriormente, analisá-los de acordo com duas perspectivas teóricas: a da Toponomástica e a da Semântica do Acontecimento.

Conforme descrito na seção de metodologia, coletamos os nomes de ruas do município de Marechal Cândido Rondon por meio do site Ruas do Brasil. Desta forma, identificamos que 14 ruas da cidade são historiotopônimos, os quais são apresentados no Quadro 1.

Quadro 1 - Amostra de historiotopônimos que são nomes de ruas do município de Marechal Cândido Rondon

\begin{tabular}{|l|l|}
\hline Rua 25 de Março & Rua 25 de Julho \\
\hline Rua 31 de Março & Rua 9 de Agosto \\
\hline Rua 2 de Abril & Rua 7 de Setembro \\
\hline Rua 8 de Abril & Rua 13 de Setembro \\
\hline Rua 10 de Abril & Rua 12 de Outubro \\
\hline Rua 22 de Abril & Rua 15 de Novembro \\
\hline Rua $1^{\circ}$ de Maio & Rua 2 de Dezembro \\
\hline
\end{tabular}

Com esta amostra, percebemos que algumas datas são de conhecimento popular, pois representam marcos históricos e feriados a nível nacional e municipal. O dia 25 de março é marcado como o Dia da Constituição, data em que a primeira Carta Constitucional do Brasil foi outorgada, em 1824, pelo imperador Dom Pedro I. O dia 31 de março lembra o Golpe de Estado, ocorrido no ano de 1964, em que os militares tomaram o governo do presidente João Goulart, instaurando uma ditadura no país, que durou 21 anos. A data 22 de abril rememora o Descobrimento do Brasil, dia em que os portugueses chegaram em território brasileiro, em 1500 . No dia $1^{o}$ de maio ,comemora-se o Dia do Trabalhador, data que remete à manifestação ocorrida nos Estados Unidos, em $1^{\circ}$ de maio de 1886, em que trabalhadores reivindicavam pela redução da carga horária máxima de trabalho por dia. No dia 25 de julho, é celebrada a emancipação do município de Marechal Cândido Rondon que, no ano de 1960, foi desmembrado dos municípios de Toledo e Foz do Iguaçu. O dia 7 de setembro recorda a Independência do Brasil, marcada pelo grito da independência, dado por D. Pedro I, em 
Onomástica Desde América Latina, n.4, v.2, julho - dezembro, 2021, p.110-129.ISSN 2675-2719 https://doi.org/10.48075/odal.v0i0.27311

1822, às margens do rio Ipiranga. Com este marco, o Brasil deixou de ser colônia portuguesa e passou a ser uma monarquia regida por D. Pedro I. A data 12 de outubro é considerada o Dia de Nossa Senhora Aparecida, imagem santa da Igreja Católica, considerada a Padroeira do Brasil. Neste dia, no ano de 1980, o Papa João Paulo II consagrou a basílica de Nossa Senhora Aparecida, localizada no município de Aparecida, em São Paulo. Anualmente, o templo recebe fiéis de todo o país para comemoração desta data. Por fim, o dia 15 de novembro remete à Proclamação da República, ocorrida no ano de 1889 e representou o fim da Monarquia Constitucional e o início da Era Republicana, com a instauração do regime presidencialista no Brasil.

Esta primeira etapa da análise dos dados revela que metade dos historiotopônimos identificados nas ruas de Marechal Cândido Rondon faz menção a fatos históricos e feriados a nível nacional.

De acordo com Seide (2010), a escolha por historiotopônimos nacionais, nesta localidade, possui relação com a história da formação do município, bem como a coerção política da época.

A região recebeu investimentos do serviço militar, tanto com a implantação de linhas telegráficas, por Marechal Rondon, como também com investimentos na agricultura durante o período do governo militar (WOLFART, 2014). Este governo, instaurado no ano de 1964, possuía caráter nacionalista. Desse modo, pode-se supor que a enunciação por trás destes historiotopônimos remete à "necessidade histórica de se afirmar a pertença da cidade formada, majoritariamente por descendentes de alemães e italianos, à nação brasileira" (SEIDE, 2010: 119).

Além disso, como comentado por Guimarães (2002), as datas que remetem a acontecimentos nacionais, na verdade, rememoram o "ser brasileiro" (GUIMARÃES, 2002: 52) pois "isto se configura não enquanto referência a fatos da história, mas como enunciados que se dão em outros textos, em outras cidades (...) a enunciação de personagens e datas da história brasileira" (GUIMARÃES, 2002: 52). Assim, a escolha de historiotopônimos vinculados às datas da história nacional, na realidade, não buscam relembrar o acontecimento em si, mas os enunciados referentes a estas datas. Vale ressaltar ainda que os mesmos historiotopônimos das ruas do município de Marechal 
Onomástica Desde América Latina, n.4, v.2, julho - dezembro, 2021, p.110-129.ISSN 2675-2719 https://doi.org/10.48075/odal.v0i0.27311

Cândido Rondon, que se referem a acontecimentos e comemorações nacionais, também se fazem presentes em outras cidades brasileiras, conforme apresentado por Guimarães (2002) e Faggion et al. (2009) ao mencionarem o historiotopônimo 7 de setembro.

Após este primeiro reconhecimento dos topônimos, investigamos acontecimentos relacionados ao município que poderiam contribuir para a identificação da motivação da escolha dos historiotopônimos, correspondendo à segunda etapa da análise. Estes dados foram coletados no acervo Memória Rondonense e no livro História e Atualidades: perfil de Marechal Cândido Rondon (WEIRICH, 2004).

Conforme descrito anteriormente, o dia 25 de março é lembrado como o Dia da Constituição. Além disso, na segunda etapa de nossa análise, identificamos que, nesta data, era comemorado o aniversário de Werno Scherer, quinto prefeito do município, que cumpriu seu mandato entre os anos de 1979 e 1985 . Scherer nasceu no estado do Rio Grande do Sul, em 1935 e mudou-se para Marechal Rondon no ano de 1953 (WEIRICH, 2004). Outro marco rememorado nesta data é a posse de Willy Barth ao cargo de diretor-gerente da Industrial Madeireira e Colonizadora Rio Paraná, em 1949 (WEIRICH, 2004).

Em relação ao dia 2 de abril, constatamos que, no ano de 1962, ocorreu o falecimento do pioneiro Willy Barth, vítima de uma síncope cardíaca (WEIRICH, 2004). Conforme descrito na seção de contextualização da pesquisa, Barth foi uma personalidade de grande importância na colonização da região Oeste do Paraná. Como forma de homenagem, seu nome também é um antropônimo de uma praça de Marechal Cândido Rondon, conforme apresentado por Seide (2010).

No dia 9 de agosto de 1972, ocorreu o falecimento do professor Waldomiro Liessen, vítima de infarto do miocárdio. Liessen iniciou sua carreira docente em 1940, no estado do Rio Grande do Sul. Ao mudar-se para Marechal Rondon, em 1955, continuou atuando na área da educação e, em 1969, assumiu o cargo de primeiro diretor do Departamento de Ensino do município (RUPPENTHAL, 2021; WEIRICH, 2004). Além deste historiotopônimo, o professor é homenageado com seu antropônimo em uma escola da cidade, como mostrado por Ruppenthal (2021). 
Onomástica Desde América Latina, n.4, v.2, julho - dezembro, 2021, p.110-129.ISSN 2675-2719 https://doi.org/10.48075/odal.v0i0.27311

$\mathrm{O}$ dia 2 de dezembro é marcado por três acontecimentos municipais. O primeiro deles aconteceu no ano de 1960, data em que o município de Marechal Cândido Rondon foi instalado, após sua emancipação. Um ano depois, em 1961, houve a posse do primeiro prefeito da cidade, Arlindo Alberto Lamb. O último marco identificado foi a criação do Departamento de Educação, no ano de 1969 (WEIRICH, 2004). Dentre estes fatos, acreditamos que o acontecimento que possa ter tido maior influência na escolha do historiotopônimo foi a instalação do município, por ser um marco de maior relevância na história da cidade.

Quanto às datas 8 de abril, 10 de abril e 13 de setembro, apesar do contato com a Prefeitura Municipal, não encontramos nenhum fato relacionado ao município que possa ter contribuído para a motivação da escolha destes historiotopônimos. Tal fato pode ser explicado por Faggion et al. (2009: 278) ao afirmarem que "no decurso do tempo, os topônimos podem ser substituídos por outros; podem sofrer alterações formais; podem perder nuances de seu significado original e podem assumir outros sentidos". Assim, na ausência de documentos oficiais que explicitem a qual fato histórico a nomeação pode ser relacionada, há uma possibilidade de os historiotopônimos em foco terem sofrido perda do significado original.

Conforme descrito na seção de fundamentação teórica, a Semântica do Acontecimento (GUIMARÃES, 2002) propõe que o ato enunciativo é realizado por um Locutor. Em nosso estudo, a enunciação corresponde à nomeação das ruas, enquanto o locutor $\mathrm{x}$, juntamente com o Locutoroficial, reproduzem o ato enunciativo. Outro ponto evidenciado por Guimarães é o fato de os nomes de rua resultarem de enunciados ditos anteriormente, assim como exemplificado pelo autor com os topônimos 7 de setembro e Baroneza Geraldo de Resende. Mediante isso, a enunciação dos nomes de rua, levando-se em conta as enunciações antecedentes, é capaz de carregar significados relacionados à cultura e à sociedade local.

Os historiotopônimos 25 de julho e 2 de dezembro rememoram datas importantes do município em questão, conforme descrito na seção anterior. Assim como acontece nos casos há pouco analisados, existe aqui a enunciação do orgulho pelo município e do pertencimento à cidade. Assim, 
Onomástica Desde América Latina, n.4, v.2, julho - dezembro, 2021, p.110-129.ISSN 2675-2719 https://doi.org/10.48075/odal.v0i0.27311

o orgulho rondonense, enunciado por outros interlocutores, em momentos anteriores, passou a ser enunciado, também, com a nomeação das ruas.

Por outro lado, os historiotopônimos 25 de março, 2 de abril e 9 de agosto, que homenageiam personalidades importantes na história do município, na verdade, representam a enunciação de locutores que consideram as pessoas em destaque importantes. Tal enunciação gera a exclusão de outras personalidades importantes que deixaram de ser homenageadas.

Apesar de Willy Barth ser o nome mais lembrado em relação à colonização da região, ele não foi o único sócio da colonizadora Maripá, nem o único colonizador da localidade. O mesmo ocorre com relação ao prefeito Werno Scherer. A possível homenagem a esta personalidade silencia outros prefeitos da cidade, que não foram homenageados. Também, a homenagem ao professor Waldomiro Liessen demonstra a exclusão de outros professores que não foram homenageados.

Percebemos, ainda, por meio dos sobrenomes de origem alemã, que os homenageados possuem ascendência germânica. Os homenageados não são oriundos da Alemanha, mas ainda carregam o sobrenome de seus antepassados germânicos, que se perpetua de geração em geração. No caso das personalidades homenageadas, elas migraram dos estados do Rio Grande do Sul e Santa Catarina para a cidade em questão no período de colonização do território. Desta forma, a escolha de historiotopônimos que remetem a estes pioneiros enuncia o desejo em caracterizar o município como sendo colonizado por povos de origem alemã.

Percebemos, então, que a escolha dos historiotopônimos para as ruas de Marechal Cândido Rondon também faz parte do interesse em tornar o município uma "cidade alemã", interesse que perpassa toda a comunidade local e participa de um embate de poder que culmina nessas nomeações, conforme explicado na seção de contextualização da pesquisa. Como consequência, este propósito silenciou as demais nacionalidades que migraram para a região, a exemplo da italiana.

É importante ressaltar que essas escolhas ilustram um interesse comum de grande parte da população do município, uma vez que permanecem através do tempo. Isso porque, de acordo com Faggion et al. (2013, p.16), 
Onomástica Desde América Latina, n.4, v.2, julho - dezembro, 2021, p.110-129.ISSN 2675-2719 https://doi.org/10.48075/odal.v0i0.27311

as denominações tornam-se parte de um "jogo" de relações que constitui a identidade de um local e notabiliza a ideologia dominante. O denominador ou ato de nomeação, ao escolher certo nome, busca no meio social, no espaço os elementos que inspirem a designação.

Desse modo, essas escolhas não representam um interesse pessoal, mas social da comunidade e, tendo em vista os silenciamentos explicitados acima, fica claro que, diante do conflito de ideologias na comunidade, um dos lados prevaleceu e pôde ser exaltado em detrimento do outro, que foi sendo cada vez mais apagado com o passar do tempo.

\section{CONSIDERAÇÕES FINAIS}

Por meio da pesquisa, demonstrou-se como os topônimos do município colaboram para o entendimento da cultura local e regional, bem como a intenção de memória e apagamento de determinados aspectos da formação da cidade. Dessa forma, as datas analisadas demonstraram a preferência por determinadas personalidades em detrimento de outras, bem como a preferência relacionada à descendência dessas personalidades homenageadas.

Ao decorrer da pesquisa, pudemos observar os esforços dos colonizadores da Companhia Maripá, e também dos prefeitos que administraram a cidade ao longo dos anos, de caracterizá-la como germânica, apagando as demais nacionalidades que fundaram a cidade e que vivem nela até hoje. Como pudemos observar, vários elementos culturais foram evocados com essa finalidade, e pudemos constatar que a escolha dos topônimos teve grande relevância dentro do conjunto de esforços.

Desse modo, foi possível notar como a escolha dos nomes das ruas tanto é influenciada pela história local, quanto influencia a cultura e a memória da cidade. Sem sabermos quem é Willy Barth, relacionamo-lo à cidade pelas diversas homenagens que ela faz a ele e assim a memória da cidade vai se constituindo, tanto através da escolha dos que serão lembrados, quanto dos que serão esquecidos.

Partindo dessas considerações, podemos finalizar nosso trabalho sugerindo investigações pertinentes à linha de pesquisa, como a análise dos nomes de ruas, estabelecimentos e instituições de Marechal Cândido Rondon pelo viés da Semântica do Acontecimento (GUIMARÃES, 2002) aliada 
Onomástica Desde América Latina, n.4, v.2, julho - dezembro, 2021, p.110-129.ISSN 2675-2719 https://doi.org/10.48075/odal.v0i0.27311

aos estudos toponímicos, a fim de identificar se os demais topônimos do município também exaltam a ascendência germânica e o desejo de pertencimento à nação brasileira.

Recebido em 01/05/2020

Aceito em 23/06/2021

Publicado em 25/08/2021

\section{REFERÊNCIAS}

Acontecimentos históricos do dia 9 de agosto. Memória Rondonense. Recuperado em 01 de fevereiro, 2021, de http://www.memoriarondonense.com.br/calendario-historico-single/08/9/.

Acontecimentos históricos do dia 25 de março. Memória Rondonense. Recuperado em 01 de fevereiro, 2021, de http://www.memoriarondonense.com.br/calendario-historico-single/03/25/.

Brandão, A. S. \& Abbade, C. M. S. (2016) Os antropotopônimos na Bahia de Todos os Santos: uma análise social e linguística. Revista GTLex, 1(2), 312-325, recuperado em 08 de abril, 2021, de http://www.seer.ufu.br/index.php/GTLex/article/view/35159.

Carvalhinhos, P. de J., \& Antunes, A. M. (2007). Princípios teóricos de toponímia e antroponímia: a questão do nome próprio. Cadernos do CNLF. Rio de Janeiro.

Chizzotti, A. (1998) Pesquisas em Ciências Humanas e Sociais. São Paulo: Cortez.

Dick, M. V. P. A. (1992) Toponímia e antroponímia no brasil: coletânea de estudos. São Paulo: FFLCH-USP.

Faggion, C. M., Dal Corno, G. O. M. \& Frosi, V. M. (2009) Topônimos de Bento Gonçalves: motivação e caracterização. MÉTIS: História e cultura, 7(13), 277-298, recuperado em 04 de abril, 2021, de http://www.ucs.br/etc/revistas/index.php/metis/article/view/704/510.

Faggion, C. M., Misturini, B., Dal Pizzol, E. V. Ideologias no ato de nomear: a toponímia revelando mudanças nas relações de poder de uma comunidade. ENTRELETRAS, Araguaína/TO, v. 4, n. 2, p. 10-30, ago./dez. 2013, recuperado em 22 de junho, 2021, de https://sistemas.uft.edu.br/periodicos/index.php/entreletras/article/view/987/526.

Frai, P. H. (2016). Motivação para a escolha de um segundo nome na antroponímia rondonense. Dissertação (Mestrado em Linguagem e Sociedade). Cascavel: Universidade Estadual do Oeste do Paraná.

Guimarães, E. (2002). Semântica do Acontecimento. Campinas-SP: Pontes.

IBGE - Instituto Brasileiro de Geografia e Estatística. (2020) Tabelas de estimativas populacionais para os municípios e para as Unidades da Federação brasileiros em 01.07.2020. Rio de Janeiro, RJ: IBGE. Recuperado em 16 de abril, 2021, de https://ftp.ibge.gov.br/Estimativas_de_Populacao/Estimativas_2020/estimativa_dou_2020.pdf. 
Onomástica Desde América Latina, n.4, v.2, julho - dezembro, 2021, p.110-129.ISSN 2675-2719 https://doi.org/10.48075/odal.v0i0.27311

Isquerdo, A. N. (1997) A toponímia como signo de representação de uma realidade. Fronteiras - Rev. História UFMS 1(2), 27-46, recuperado em 14 de abril, 2021, de https://ojs.ufgd.edu.br/index.php/FRONTEIRAS/article/view/12920/6281.

Kerkhoven, R. C. \& Seide, M. S. (2018) Os nomes de edifícios em Marechal Cândido Rondon: estudo exploratório. Revista Linguasagem, 28(1), 365-387, ISSN: 1983-6988, recuperado em 12 de abril, 2021, de http://www.linguasagem.ufscar.br/index.php/linguasagem/article/view/378/223.

KRIPKA, R. M. L., SCHELlER, M. \& BONOTTO, D. de L. (2015) Pesquisa documental na pesquisa qualitativa: conceitos e caracterização. Revista de Investigaciones UNAD, 14 (2), 55-73, recuperado em 12 de abril, 2021, de https://core.ac.uk/download/pdf/322589335.pdf.

Lista de ruas em Marechal Cândido Rondon. Ruas do Brasil. Recuperado em 29 de janeiro, 2021, de https://ruas-brasil.openalfa.com/marechal-candido-rondon.

Mendes, C. M., Souza, J. \& Silva, S. M. R. D. (2020) A noção de acontecimento à luz da Análise do Discurso, da Semântica do Acontecimento e da Semiótica Tensiva. Linguagem em (Dis)curso LemD, 20 (1), 179-195, recuperado em 14 de abril, 2021, de http://www.portaldeperiodicos.unisul.br/index.php/Linguagem_Discurso/article/view/6667/4906.

Ruppenthal, D. S. (2021) Nomeação de escolas como homenagem à histórica local do município paranaense de Marechal Cândido Rondon. Onomástica desde América Latina, 2 (3), 154-176, ISSN 2675-2719. Recuperado em 12 de abril, 2021, de https://doi.org/10.48075/odal.v0i0.25692.

Seide, M. S. (2010). Nomes de lugares: o viés enunciativo e o viés onomástico. In: A. N. Isquerdo. As Ciências do Léxico: Lexicologia, Lexicografia, Terminologia, 117-133, recuperado em 03 de fevereiro, 2021 , http://www.letras.ufmg.br/padrao_cms/documentos/eventos/gtlex/viiengtlex/resumos_expandidos/ marciaSipaviciusSEIDE.pdf.

Seide, M. S, \& Lucas, P. (2018). Os topônimos comerciais da cidade de Naranjal, Paraguai. Confluência, 1(54), 164-195. doi:http://dx.doi.org/10.18364/rc.v1i54.238

Silva, B. N. \& Seide, M. S. (2017) Desigualdade de gênero na toponímia: um estudo exploratório. Revista GTLex, 3(1), 133-145. ISSN: 2447-9551. DOI: 10.14393/Lex5-v3n1a2017-8.

Sousa, A. \& Martins, R. M. (2017) A motivação toponímica na escolha dos nomes geográficos de origem indígena da zona rural da região do baixo Acre. Revista Tropos, 6(2), 1-16, recuperado em 14 de abril, 2021, de https://periodicos.ufac.br/index.php/tropos/article/view/1291.

Tozoni-Reis, M. F. D. (2009) Metodologia da Pesquisa. (2a ed.) Curitiba: IESDE Brasil S.A.

Weirich, U. L. (2004) História e atualidades: perfil de Marechal Cândido Rondon. Marechal Cândido Rondon: Germânica.

Wolfart, C (2014). Acarpa e Clube 4-S: a modernização da agricultura em Marechal Cândido Rondon/PR (1960-1970). Revista Vernáculo, 34(1). DOI: http://dx.doi.org/10.5380/rv.v0i34.37199. 